\title{
Commercial Monomer Availability Leading to Missed Opportunities? Anion-Exchange Membranes Made from meta-Vinylbenzyl Chloride Exhibit an Alkali Stability Enhancement
}

\author{
Julia Ponce-González,*i( John R. Varcoe, and Daniel K. Whelligan \\ Department of Chemistry, The University of Surrey, Guildford GU2 7XH, United Kingdom
}

Supporting Information
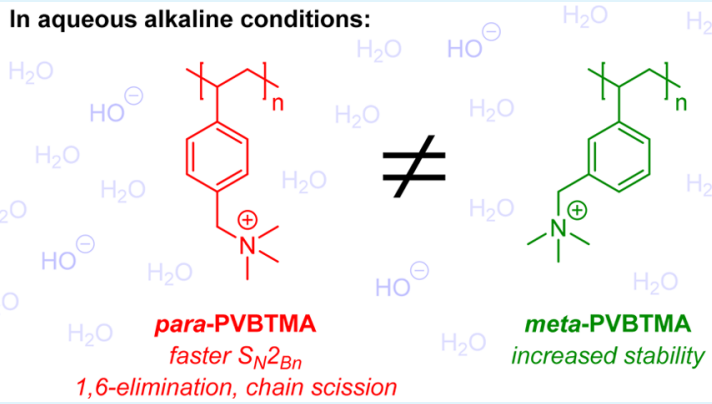

ABSTRACT: Benzyltrimethylammonium-type anion-exchange polymers are common in alkali membrane fuel cells and water electrolyzers, but they suffer from degradation under alkaline conditions. Radiation-grafted anion-exchange membranes exhibit an alkali stability enhancement when made using noncommercial meta-only vinylbenzyl chloride (VBC) monomer, compared to the use of commercially available para-only or meta/para-mixed VBC isomers. We hypothesize a mechanism on why the use of metaVBC eliminates AEM degradation via chain scission.

KEYWORDS: anion-exchange membranes, alkaline membrane fuel cells, water electrolyzers, vinylbenzyl chloride, benzyltrimethylammonium, 1,6-elimination, ultrasound-assisted grafting, radiation-induced grafting

$\mathrm{P}$ oly(vinylbenzyltrimethylammonium) (PVBTMA) chemistry is common in anion-exchange polymers due to the facile polymerization of styrenic vinyl groups and their ease of synthesis via monomers containing highly reactive benzylic chloride functionality (used to introduce target quaternary ammonium (QA) groups). ${ }^{1-6}$ For this reason it has been extensively employed in anion-exchange membranes (AEMs) and ionomers (AEI) for use in alkali membrane fuel cells and electrolyzers. However, this chemistry lacks the necessary stability at $>60{ }^{\circ} \mathrm{C}$, especially when the AEMs/AEIs are less hydrated. ${ }^{7,8}$ Hence, more alkali robust QA chemistries are required. ${ }^{9}$

The degradation of benzyltrimethylammonium cations (BTMA, $\mathrm{C}_{6} \mathrm{H}_{5} \mathrm{CH}_{2} \mathrm{NMe}_{3}{ }^{+}$) in alkali media has been widely studied, and the benzylic carbon ( $\alpha$ to the QA group) is most sensitive to $\mathrm{OH}^{-}$attack: ${ }^{10-13}$ This results in displacement of the QA group by an $S_{N} 2_{B n}$ mechanism (or via an ylide) yielding benzyl alcohol and trimethylamine. ${ }^{14} \mathrm{~A}$ recent approach to reduce this has been to introduce aliphatic "spacers" between the QA and aromatic groups. ${ }^{15}$ Our attempt at this strategy resulted in a radiation-grafted AEM with reduced ion-exchange capacity (IEC) and conductivity. ${ }^{16}$ An alternative strategy is therefore sought.

As mentioned by Hickner, ${ }^{18}$ if the transition state (TS) involves the development of positive charge at the benzylic carbon, then electron-donating substituents will increase the rate of $S_{N} 2_{B n}$ reaction. The modified Hammett parameter $\sigma^{+}$ quantifies the ability of a substituent to do this and is increasingly negative for stronger electron-donating substituents. An isopropyl group, representative of a PVBTMA backbone, has $\sigma^{+}=-0.06$ in the meta-position and -0.28 in the para-position (hereafter referred to as the 3- and 4positions, respectively), predicting an increased rate of hydrolysis for the 4-isomer (the partial positive charge can be stabilized by hyperconjugation from the 4- but not the 3position). ${ }^{17}$ We therefore hypothesized that 3-PVBTMA would be significantly more stable to alkaline hydrolysis than 4PVBTMA.

PVBTMA-type polymers have been shown to degrade in solution not only by the same degradation mechanisms as the BTMA molecule itself, but also via other mechanisms that give rise to additional byproducts. ${ }^{18,19}$ A previous study observed the loss of pendant BTMA moieties upon the alkali treatment of ETFE-based PVBTMA-grafted AEMs. ${ }^{20}$ This was evidenced by the change of integration of the aromatic peaks, with respect to the ETFE bands, after treatment in aqueous $\mathrm{KOH}(1 \mathrm{M})$ at $80^{\circ} \mathrm{C}$ for 28 days, in both the Raman and solid state NMR (SS-

Received: March 19, 2018

Accepted: April 13, 2018

Published: April 13, 2018 
NMR) spectra. This result suggests that a scission of the grafted chains could be taking place, a phenomenon also observed by Espiritu et al. with LDPE-based PVBTMA-grafted AEMs. ${ }^{21}$ Since the resulting PVBTMA degradation fragments are soluble in water, they could be washed out of the degrading AEM, leading to a loss of IEC. A mechanism which supports such degradation was recently proposed by Hickner and involves a 1,6-Hofmann-type elimination (labeled "1,4-elimination" in their paper). ${ }^{19}$ This was shown as early as 1960 to occur in 4methylbenzyltrimethylammonium hydroxide heated at 60-100 ${ }^{\circ} \mathrm{C} .{ }^{22}$ Degradation proceeds via a 1,4-quinodimethane-like intermediate, and we propose (Scheme 1, vide infra) that the

Scheme 1. Proposed Alkali-Mediated 1,6-Elimination and Chain Scission Mechanism on PVBTMA Polycations

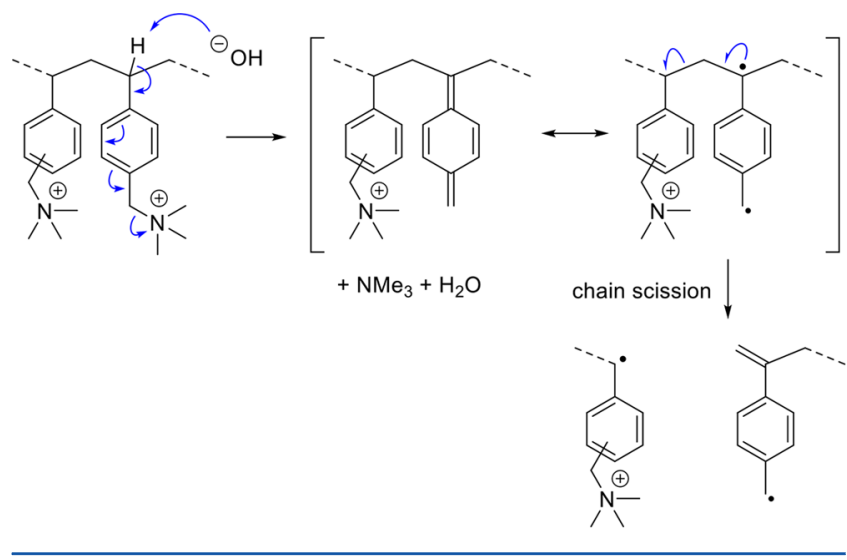

diradical resonance form of this could fragment and/or depolymerize. It is important to note that only 4- and 2substituted benzene rings are able to form quinone-like structures; thus, 3-PVBTMA would not be susceptible to this mechanism.

While evidence to distinguish between the degradation products of $S_{\mathrm{N}} 2_{\mathrm{Bn}}$ and 1,6-elimination mechanisms could not be obtained, small molecule degradation tests by Hickner et al. revealed that 4-methylbenzyltrimethylammonium groups degrade faster than BTMA. This suggests that the presence of 4methyl groups accelerates degradation, either through 1,6elimination or stabilized $\mathrm{S}_{\mathrm{N}} 2_{\mathrm{Bn}}$. ${ }^{19}$

The evidence against 4-PVBTMA-grafted groups being stable in alkali media motivated us to compare the separate 3- and 4isomeric forms of our radiation-grafted AEMs. Thus, the alkali stabilities of ETFE-g-PVBTMA AEMs, prepared separately from pure 3-VBC, pure 4-VBC, and the 3-/4-VBC mixture (1:1 ratio determined by NMR, see Figure $\mathrm{S} 8$ in Supporting Information), were studied. 4-VBC and 3-/4-VBC mixed monomers are commercially available but not $3-\mathrm{VBC}$, so a novel three-step synthesis was developed (detailed in the Supporting Information). This involved THP-protection of 3bromobenzyl alcohol ${ }^{23}$ followed by conversion to the Grignard reagent and Fe-mediated coupling with vinylacetate. ${ }^{24}$ Final alcohol deprotection and conversion to the chloride occurred in one step using dichloromethylene-dimethyliminium chloride. $^{25}$

For the grafting step (Scheme 2), preirradiated ETFE films (40 kGy absorbed dose) were immersed in aqueous mixtures of the corresponding VBC monomer $(5 \% \mathrm{v} / \mathrm{v})$ and wetting agent (1-octyl-2-pyrrolidone, $1 \% \mathrm{v} / \mathrm{v}$ ), purged with $\mathrm{N}_{2}$ for $2 \mathrm{~h}$ and then treated in an ultrasound bath at $70{ }^{\circ} \mathrm{C} .{ }^{26}$ As reported
Scheme 2. Synthesis of ETFE-Based Radiation-Grafted AEMs with Different VBC Isomers Compositions

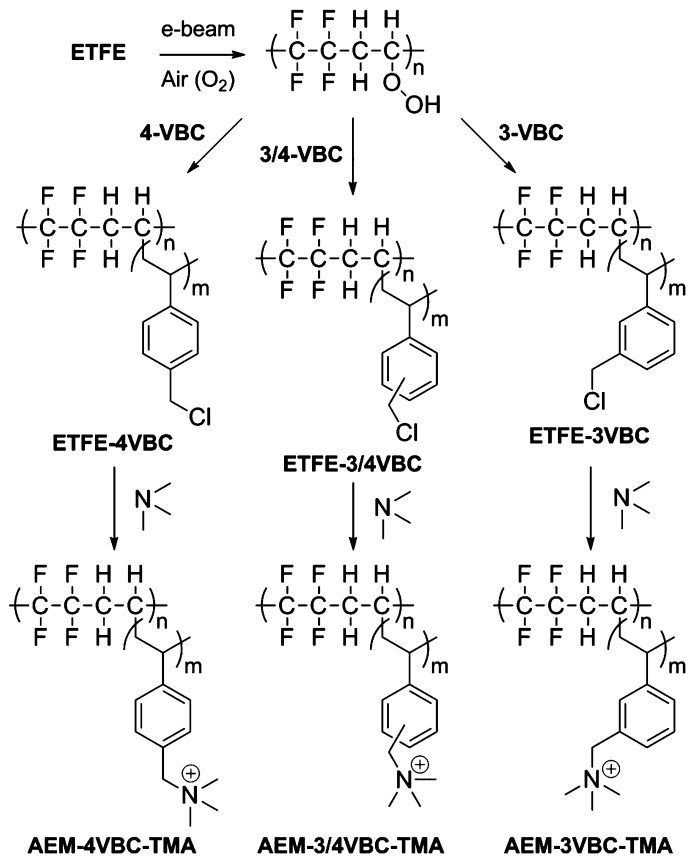

previously, ${ }^{16}$ the use of ultrasound was found to be necessary to avoid the formation of homopolymer during grafting. To minimize synthetic variables, the same sonication input was applied with all three VBC monomers. In the first instance, the ultrasound-assisted grafting was carried out over a period of $6 \mathrm{~h}$, and this produced grafted intermediate ETFE-VBC membranes with degrees of grafting (DoG) of $94 \%, 55 \%$, and $29 \%$ with 4VBC, 3/4-VBC mixture, and 3-VBC, respectively (see Table S3 in the Supporting Information). This highlights the different reactivities of the isomers with 4-VBC affording a much higher DoG for the same grafting time. A related phenomenon has been reported for nitroxide-mediated polymerization of $\mathrm{VBC}$, although 3/4-monomer mixtures showed only marginally faster conversion of the $4-\mathrm{VBC}$, and mixtures containing a higher content of 4-VBC yielded higher molecular weight polymers (albeit with higher polydispersity index due to increased chain transfer events with 4-VBC). ${ }^{27}$ In our work, as radiationgrafting is a radical polymerization process, this may translate to faster grafting when using pure 4-VBC. In both cases, this is likely due to increased stabilization of the intermediate 4substituted benzyl radical by hyperconjugation with the backbone alkyl group which is not possible for the 3-substituted analogue.

Our prior experience has indicated that an AEM's IEC has a significant influence on its $e x$-situ alkali degradation rate. This was observed for two radiation-grafted AEMs with different IECs that were prepared with the same chemistries and grafting conditions (using different batches of mixed 3/4-isomer VBC, Table $S 1$ in the Supporting Information). Upon treatment with aqueous $\mathrm{KOH}(1 \mathrm{M})$ at $80{ }^{\circ} \mathrm{C}$ for 28 days, AEM-a (original IEC $\left.=1.85 \mathrm{mmol} \mathrm{g}^{-1}\right)$, experienced an IEC loss of $35 \%$ whereas AEM-b (original IEC $=2.12 \mathrm{mmol} \mathrm{g}^{-1}$ ) lost just $16 \%$. This agrees with the prior literature in that this behavior derives from different water contents. Higher $\mathrm{OH}^{-}$hydration reduces this anion's nucleophilicity, resulting in reduction in the alkali degradation of the polycationic chains. ${ }^{8}$ AEM-b presented a $\lambda$ 
Table 1. Key Grafting Variables and Properties of the AEMs Produced ${ }^{a}$

$\begin{array}{llcc} & \text { AEM-4VBC-TMA } & \text { AEM-3/4VBC-TMA } & \text { AEM-3VBC-TMA } \\ \text { monomer [\% v/v] } & 5 & 5 & 6 \\ \text { reaction time/h } & 1 & 2 & 6 \\ \text { DoG [\%] } & 61 & 54 & 27 \\ \text { IEC } / \mathrm{mmol} \mathrm{g}{ }^{-1} & 1.88 \pm 0.02 & 1.86 \pm 0.08 & 1.13 \pm 0.02 \\ \text { WU [\%] } & 51 \pm 4 & 51 \pm 4 & 16 \pm 3 \\ \lambda & 15.0 \pm 1.1 & 15.1 \pm 1.4 & 8.1 \pm 1.3 \\ \text { IEC loss [\%] } & 54 \pm 2 & 37 \pm 5 & 26 \pm 3\end{array}$

${ }^{a}$ Errors are from repeat measurements on $n=4$ samples of each AEM.

value (number of $\mathrm{H}_{2} \mathrm{O}$ per cationic group) of 18 whereas that of AEM-a was $\lambda=13$.

Given the above, our desire was to test the isomer effect on the stability of the AEMs of similar IEC with each VBC monomer. By decreasing the reaction time during the grafting step, the DoG of ETFE-4VBC and ETFE-3/4VBC reduced to $54 \%$ and $61 \%$, respectively. However, we could not obtain a DoG $>27 \%$ for ETFE-3VBC. VBC grafting was confirmed using Raman spectroscopy (Figure S9 of the Supporting Information). The different isomers produced distinctive spectra. ETFE-4VBC yielded an intense peak at $1615 \mathrm{~cm}^{-1}$ and two peaks around $1200 \mathrm{~cm}^{-1}$ (all related to the aromatic ring), whereas ETFE-3VBC yielded two peaks at 1000 and 700 $\mathrm{cm}^{-1}$ (highly characteristic of meta-disubstituted benzene rings). ${ }^{20,28}$ The spectrum of ETFE-3/4VBC combines the spectral features of the two pure isomer AEMs, proving the grafted chains contain both isomers.

Next, the three grafted ETFE-VBC intermediates were quaternized with aqueous trimethylamine (TMA, $45 \% \mathrm{v} / \mathrm{v}$ ) at room temperature for $24 \mathrm{~h}$. The main properties of the resulting AEMs are summarized in Table 1. Despite our intentions, the IEC and $\lambda$ of AEM-3VBC-TMA were significantly lower. Considering the above discussions, our concern now was that this additional variable would have a negative effect on the alkali stability of the AEM. Nevertheless, AEM-3VBC-AEM actually showed significantly less alkali degradation than AEM-4VBC-AEM. Furthermore, the AEM produced from the $3 / 4 \mathrm{VBC}$ isomer mixture (with essentially the same IEC and $\lambda$ to AEM-4VBC-TMA) showed an intermediate degree of alkali-mediated degradation.

Figure 1 shows a comparison of the SS-NMR spectra of the pre- and post-alkali-treated samples of the three AEMs. As expected, AEM-4VBC-TMA reported a significant loss of intensity of the peaks related to the QA methyl carbon atoms $(\delta=53 \mathrm{ppm})$, the benzyl- $\mathrm{CH}_{2}(\delta=69 \mathrm{ppm})$, as well as the $\operatorname{aromatic}(\delta=146,131,118 \mathrm{ppm})$ and aliphatic $(\delta=47,41$ ppm) related peaks derived from the grafted chains. These intensity decreases were also observed, to a lesser extent, for the AEM-3/4VBC-TMA. In contrast, negligible changes to the spectra of AEM-3VBC-TMA upon alkali treatment were seen. Analogous trends were observed using Raman spectroscopy (Figure 2). AEM-4VBC-TMA showed a significant intensity decrease of bands corresponding to the aromatic ring (1615, 1215 , and $1181 \mathrm{~cm}^{-1}$ ) and to the QA (around $900 \mathrm{~cm}^{-1}$ ), ${ }^{29}$ whereas the ETFE-derived band $\left(1445 \mathrm{~cm}^{-1}\right)$ remained relatively unchanged. In contrast, no significant intensity changes were observed for the alkali-treated AEM-3VBCTMA. The spectra for AEM-3/4VBC-TMA showed intermediate levels of intensity losses for the aromatic bands (and the $1000 \mathrm{~cm}^{-1}$ band related to the 3 -isomer). Although the 3-

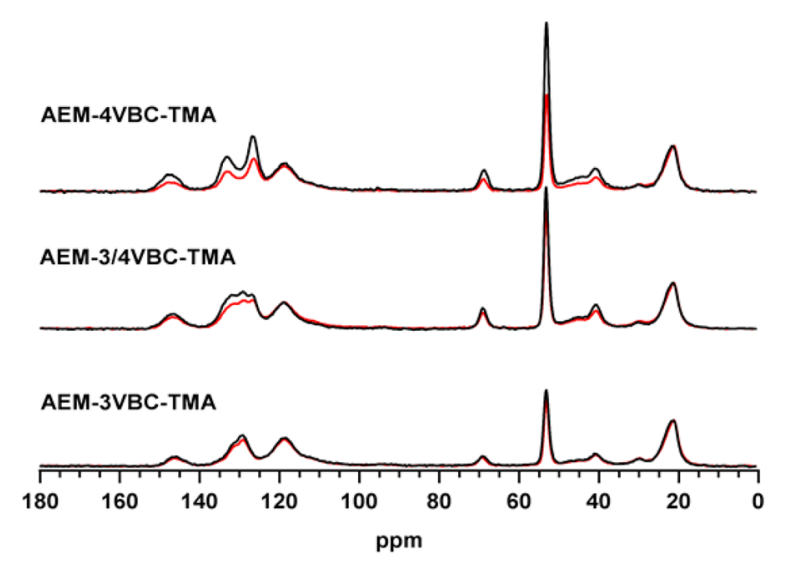

Figure $1 .{ }^{13} \mathrm{C}$ SS-NMR spectra of the AEMs before (black) and after (red) alkali treatment in aqueous $\mathrm{KOH}(1 \mathrm{M})$ at $80^{\circ} \mathrm{C}$ for 28 days. All spectra have been normalized to the intensity of the $\delta=22$ band (ETFE's methylene $\mathrm{CH}_{2}$ ).

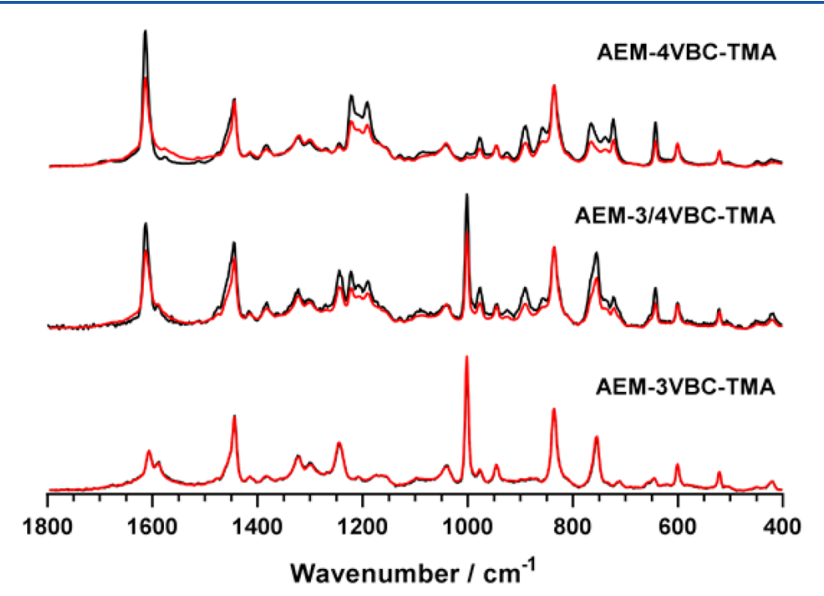

Figure 2. Raman spectra recorded on the surface of the AEMs before (black) and after (red) ex-situ alkali treatment in aqueous $\mathrm{KOH}(1 \mathrm{M})$ at $80{ }^{\circ} \mathrm{C}$ for 28 days. All spectra have been normalized to the ETFE $830 \mathrm{~cm}^{-1}$ band.

isomer is less susceptible to 1,6-elimination, chain scission would lead to the loss of both monomers.

Thus, post-mortem sample analysis by IEC (Figure 3), SSNMR, and Raman spectroscopy provides evidence of the superior alkaline stability of 3- over 4-PVBTMA-grafted chains. The spectral data shows that 4-PVBTMA-grafted chains are affected by a degradation mechanism that causes scission of the grafted chain, with a large impact on the IEC. We propose that this mechanism (Scheme 1) initially involves a $\mathrm{OH}^{-}$-promoted 1,6-elimination of the TMA-based QA group to give a 1,4quinodimethane-like intermediate whose resonance form is a 


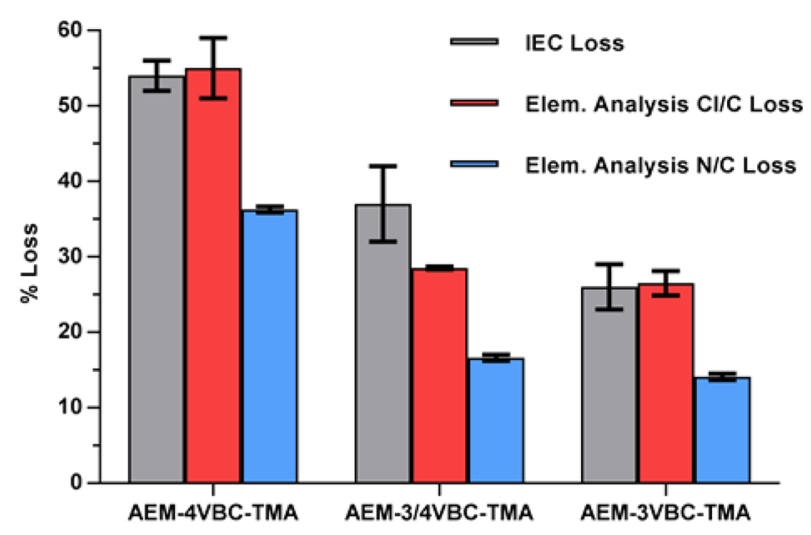

Figure 3. Percent loss of IEC and losses of $\mathrm{Cl} / \mathrm{C}$ and $\mathrm{N} / \mathrm{C}$ molar ratios (the latter extracted from elemental analyses) of the AEM samples after $e x$-situ alkali treatment in aqueous $\mathrm{KOH}(1 \mathrm{M})$ at $80^{\circ} \mathrm{C}$ for 28 days.

diradical. The radical at the benzylic position of the polymer backbone can then fragment the chain to cause the observed scission, after which the resulting new benzylic radical could go on to further depolymerize the polymer until a termination event takes place. This mechanism is similar to one proposed by Hirao et al. to explain the undesired formation of crosslinked polymers in the anionic living polymerization of 4substituted vinylbenzenes (which did not occur with their 3analogues). ${ }^{30,31}$

We also evaluated the degradation in terms of $\mathrm{N}$ and $\mathrm{Cl}$ atom loss by conducting elemental analysis on the pre- and posttreated samples (Figure 3 and Table S2 of the Supporting Information). This method enables us to separately quantify degradation that involves loss of $\mathrm{N}$ atoms and compare it to overall loss of positive charge (observed as a reduction in $\mathrm{Cl}^{-}$ ion content). ${ }^{20}$ For AEM-4VBC-TMA, the majority of the degradation takes place with loss of the $\mathrm{N}$ atoms, which can be ascribed to $S_{\mathrm{N}} 2_{\mathrm{Bn}}$ hydrolysis and 1,6-elimination. In the case of AEM-3VBC-TMA, the loss of $\mathrm{N}$ atoms is reduced, which reflects either a lower propensity for $\mathrm{S}_{\mathrm{N}} 2_{\mathrm{Bn}}$ hydrolysis and/or its inability to undergo 1,6-elimination. Recall that, for AEM3VBC-TMA, alkali degradation was initially expected to be higher due to its low $\lambda$.

As an aside, we also aminated ETFE-4VBC-, ETFE-3/ 4VBC-, and ETFE-3VBC-grafted intermediates with $\mathrm{N}$ methylpyrrolidine (MPY), which we have found in previous work to produce more alkali-stable AEMs (cf. TMA-types). ${ }^{20}$ Analogous trends were observed: AEM-4VBC-MPY showed the highest IEC loss on alkali treatment, and AEM-3VBC-MPY was the most alkali-stable AEM tested despite having a much lower $\lambda$ (Table S3 in the Supporting Information).

In summary, ex-situ stability tests evidenced that anionexchange membranes (AEM) made from radiation-grafted poly(vinylbenzyltrimethylammonium) (PVBTMA) groups onto ETFE films are more chemically resistant in aqueous alkali media when the benzyl groups are meta-substituted (cf. when they are para-substituted). We hypothesize that this results from two effects: (1) an increased propensity of the para-substituted PVBTMA grafts to undergo $\mathrm{S}_{\mathrm{N}} 2_{\mathrm{Bn}}$ hydrolysis by $\mathrm{OH}^{-}$anions due to the ability of the para-alkyl group (grafted polymer hydrocarbon backbone) to stabilize the developing positive charge on the benzylic $\mathrm{C}$ atom in the transition state, and (2) the ability of para-substituted PVBTMA grafts to undergo an additional degradation mechanism involving base-promoted 1,6-elimination of the QA headgroup. Furthermore, we have shown that the parasubstituted AEM also suffers from loss of aromatic groups, and this likely arises from chain scission caused by the intermediate diradical in the 1,6-elimination pathway. This finding has a major impact on the field due to the widespread use of PVBTMA in polymer electrolytes. One disadvantage of the use of the meta-vinylbenzyl chloride (VBC) monomer was its reduced degree of grafting compared to that for para-VBC, which led to an AEM with an undesirable low ion-exchange capacity. While our next challenge is to improve its degree of grafting for synthesizing this type of radiation-grafted AEM, this important finding (it produces more alkali-stable polymers compared to the commercially available isomers) will be of use to other researchers who are developing other types of alkalistable anion-exchange polymer electrolytes.

This work also contributes to the body of knowledge regarding the role of hydration on the stability of AEMs. A higher number of solvating $\mathrm{H}_{2} \mathrm{O}$ molecules (causes lower nucleophilicity of $\mathrm{OH}^{-}$ions) leads to more stable AEMs (with comparable quaternary ammonium chemistries). However, higher water uptakes can lead to increased swelling and reduced mechanical stabilities. For each polymer system, an optimum IEC will balance maximized ion conductivity with nonexcessive water uptake and minimized alkali degradation.

\section{ASSOCIATED CONTENT}

\section{(5) Supporting Information}

The Supporting Information is available free of charge on the ACS Publications website at DOI: 10.1021/acsaem.8b00438.

3 -VBC synthetic procedures with compound characterization data and NMR spectra, AEM preparation procedures with associated characterization data and Raman spectra, the ex-situ alkali test procedure, and elemental analysis data (PDF)

\section{AUTHOR INFORMATION}

\section{Corresponding Author}

*E-mail: jupongon@gmail.com.

ORCID

Julia Ponce-González: 0000-0002-3317-1207

\section{Author Contributions}

The experimental work and most of the data analyses were conducted by J.P.-G. She also drafted the initial version of this article. J.R.V. was the principal investigator for the grant and directly participated with results interpretation and in the writing of the article. D.K.W. directly supervised the synthesis of the $3-\mathrm{VBC}$ monomer and was instrumental in the analysis of the data related to AEM degradation; he also directly participated in the writing of the article.

\section{Notes}

The authors declare no competing financial interest.

\section{ACKNOWLEDGMENTS}

The research was funded by EPSRC Grant EP/M005933/1.

\section{REFERENCES}

(1) Tomoi, M.; Yamaguchi, K.; Ando, R.; Kantake, Y.; Aosaki, Y.; Kubota, H. Synthesis and Thermal Stability of Novel Anion Exchange Resins with Spacer Chains. J. Appl. Polym. Sci. 1997, 64, 1161-1167.

(2) Zhang, C.; Hu, J.; Meng, Y.; Nagatsu, M.; Toyoda, H. Preparation of High-Performance Hydroxide Exchange Membrane by a Novel 
Ablation Restriction Plasma Polymerization Approach. Chem. Commun. (Cambridge, U. K.) 2011, 47, 10230-10232.

(3) Yang, Y.; Knauss, D. M. Poly(2,6-Dimethyl-1,4-Phenylene Oxide)- B -Poly(vinylbenzyltrimethylammonium) Diblock Copolymers for Highly Conductive Anion Exchange Membranes. Macromolecules 2015, 48, 4471-4480.

(4) Wang, L.; Hickner, M. A. Highly Conductive Side Chain Block Copolymer Anion Exchange Membranes. Soft Matter 2016, 12, 53595371.

(5) Xue, J.; Liu, L.; Liao, J.; Shen, Y.; Li, N. UV-Crosslinking of Polystyrene Anion Exchange Membranes by Azidated Macromolecular Crosslinker for Alkaline Fuel Cells. J. Membr. Sci. 2017, 535, 322-330.

(6) Luo, Y.; Guo, J.; Wang, C.; Chu, D. Tunable High-MolecularWeight Anion-Exchange Membranes for Alkaline Fuel Cells. Macromol. Chem. Phys. 2011, 212, 2094-2102.

(7) Dekel, D. R.; Willdorf, S.; Ash, U.; Amar, M.; Pusara, S.; Dhara, S.; Srebnik, S.; Diesendruck, C. E. The Critical Relation between Chemical Stability of Cations and Water in Anion Exchange Membrane Fuel Cells Environment. J. Power Sources 2018, 375, $351-360$.

(8) Dekel, D. R.; Amar, M.; Willdorf, S.; Kosa, M.; Dhara, S.; Diesendruck, C. E. Effect of Water on the Stability of Quaternary Ammonium Groups for Anion Exchange Membrane Fuel Cell Applications. Chem. Mater. 2017, 29, 4425-4431.

(9) Varcoe, J. R.; Atanassov, P.; Dekel, D. R.; Herring, A. M.; Hickner, M. A.; Kohl, P. A.; Kucernak, A. R.; Mustain, W. E.; Nijmeijer, K.; Scott, K.; Xu, T.; Zhuang, L. Anion-Exchange Membranes in Electrochemical Energy Systems. Energy Environ. Sci. 2014, 7, 3135-3191.

(10) Mohanty, A. D.; Bae, C. Mechanistic Analysis of Ammonium Cation Stability for Alkaline Exchange Membrane Fuel Cells $\dagger$. J. Mater. Chem. A 2014, 2, 17314-17320.

(11) Chempath, S.; Einsla, B. R.; Pratt, L. R.; Macomber, C. S.; Boncella, J. M.; Rau, J. A.; Pivovar, B. S. Mechanism of Tetraalkylammonium Headgroup Degradation in Alkaline Fuel Cell Membranes. J. Phys. Chem. C 2008, 112, 3179-3182.

(12) Marino, M. G.; Kreuer, K. D. Alkaline Stability of Quaternary Ammonium Cations for Alkaline Fuel Cell Membranes and Ionic Liquids. ChemSusChem 2015, 8, 513-523.

(13) Sturgeon, M. R.; Macomber, C. S.; Engtrakul, C.; Long, H.; Pivovar, B. S. Hydroxide Based Benzyltrimethylammonium Degradation: Quantification of Rates and Degradation Technique Development. J. Electrochem. Soc. 2015, 162, F366-F372.

(14) Chempath, S.; Boncella, J. M.; Pratt, L. R; Henson, N.; Pivovar, B. S. Density Functional Theory Study of Degradation of Tetraalkylammonium Hydroxides. J. Phys. Chem. C 2010, 114, 11977-11983.

(15) Jannasch, P.; Weiber, E. A. Configuring Anion-Exchange Membranes for High Conductivity and Alkaline Stability by Using Cationic Polymers with Tailored Side Chains. Macromol. Chem. Phys. 2016, 217, 1108-1118.

(16) Ponce-González, J.; Ouachan, I.; Varcoe, J. R.; Whelligan, D. K. Radiation-Induced Grafting of a Butyl-Spacer Styrenic Monomer onto ETFE: The Synthesis of the Most Alkali Stable Radiation-Grafted Anion-Exchange Membrane to Date. J. Mater. Chem. A 2018, 6, 823827.

(17) Okamoto, Y.; Brown, H. C. A Quantitative Treatment for Electrophilic Reactions of Aromatic Derivatives1-3. J. Org. Chem. 1957, 22, 485-494.

(18) Meek, K. M.; Nykaza, J. R.; Elabd, Y. A. Alkaline Chemical Stability and Ion Transport in Polymerized Ionic Liquids with Various Backbones and Cations. Macromolecules 2016, 49, 3382-3394.

(19) Nuñez, S. A.; Capparelli, C.; Hickner, M. A. N -Alkyl Interstitial Spacers and Terminal Pendants Influence the Alkaline Stability of Tetraalkylammonium Cations for Anion Exchange Membrane Fuel Cells. Chem. Mater. 2016, 28, 2589-2598.

(20) Ponce-Gonzalez, J.; Whelligan, D. K.; Wang, L.; Bance-Soualhi, R.; Wang, Y.; Peng, Y.; Peng, H.; Apperley, D. C.; Sarode, H. N.; Pandey, T. P.; Divekar, A. G.; Seifert, S.; Herring, A.; Zhuang, L.;
Varcoe, J. R. High Performance Aliphatic-Heterocyclic BenzylQuaternary Ammonium Radiation-Grafted Anion-Exchange Membranes. Energy Environ. Sci. 2016, 9, 3724-3735.

(21) Espiritu, R.; Golding, B. T.; Scott, K.; Mamlouk, M. Degradation of Radiation Grafted Hydroxide Anion Exchange Membrane Immersed in Neutral pH: Removal of Vinylbenzyl Trimethylammonium Hydroxide due to Oxidation. J. Mater. Chem. A 2017, 5, 12481267.

(22) Winberg, H. E.; Fawcett, F. S.; Mochel, W. E.; Theobald, C. W. Dimethylenedihydroheteroaromatic Compounds and Heterocyclophanes by 1,6-Hofmann Elimination Reactions. J. Am. Chem. Soc. 1960, 82, 1428-1435.

(23) Delorme, D.; Ducharme, Y.; Brideau, C.; Chan, C. C.; Chauret, N.; Desmarais, S.; Dubé, D.; Falgueyret, J. P.; Fortin, R.; Guay, J.; Hamel, P.; Jones, T. R.; Lépine, C.; Li, C.; McAuliffe, M.; McFarlane, C. S.; Nicoll-Griffith, D.; Riendeau, D.; Yergey, J.; Girard, Y. Dioxabicyclooctanyl Naphthalenenitriles as Nonredox 5-Lipoxygenase Inhibitors: Structure-Activity Relationship Study Directed toward the Improvement of Metabolic Stability. J. Med. Chem. 1996, 39, 39513970.

(24) Gärtner, D.; Stein, A. L.; Grupe, S.; Arp, J.; Von Wangelin, A. J. Iron-Catalyzed Cross-Coupling of Alkenyl Acetates. Angew. Chem., Int. Ed. 2015, 54, 10545-10549.

(25) Schlama, T.; Gouverneur, V.; Mioskowski, C. oB Me fPh. Tetrahedron Lett. 1997, 38, 3517-3520.

(26) Wang, L.; Magliocca, E.; Cunningham, E. L.; Mustain, W. E.; Poynton, S. D.; Escudero-Cid, R.; Nasef, M. M.; Ponce-González, J.; Bance-Souahli, R.; Slade, R. C. T.; Whelligan, D. K.; Varcoe, J. R. An Optimised Synthesis of High Performance Radiation-Grafted AnionExchange Membranes. Green Chem. 2017, 19, 831-843.

(27) Bultz, E.; Bender, T. P. NMP of Chloromethylsytrene with Minimized PDI: The Role of the Initiator/nitroxide System and the Meta Isomer. Macromolecules 2011, 44, 3666-3669.

(28) Larkin, P. Infrared and Raman Spectroscopy; Principles and Spectral Interpretation; Elsevier Science, 2011.

(29) Wang, L.; Brink, J. J.; Liu, Y.; Herring, A. M.; Ponce-González, J.; Whelligan, D. K.; Varcoe, J. R. Non-Fluorinated Pre-IrradiationGrafted (Peroxidated) LDPE-Based Anion-Exchange Membranes with High Performance and Stability. Energy Environ. Sci. 2017, 10, 21542167.

(30) Ishizone, T.; Kato, R.; Ishino, Y.; Hirao, A.; Nakahama, S. Protection and Polymerization of Functional Monomers. 15. Anionic Living Polymerizations of 2-(3-Vinylphenyl)-1,3-Dioxolane and Related Monomers. Macromolecules 1991, 24, 1449-1454.

(31) Loykulnant, S.; Yamashiro, M.; Hirao, A. Protection and Polymerization of Functional Monomers, 31. Living Anionic Polymerization of Styrene Derivativesm, $\mathrm{m}^{\prime}$-Disubstituted with Acetal-Protected Monosaccharide Residues. Macromol. Chem. Phys. 2001, 202, 1791-1798. 